\title{
Theoretical Calculation of Polymeric Nano-Composite Interface: A Review
}

\author{
Wei Huang ${ }^{\mathrm{a} 1}$, Jia-qi Lin ${ }^{\mathrm{b} 1}$, Wen-long Yang ${ }^{\mathrm{c}{ }^{*}}$ and Yu Wang ${ }^{\mathrm{d} 1}$ \\ ${ }^{1}$ Academy of Applied Science, Harbin University of Science and Technology, Heilongjiang \\ 150080, China \\ yangwenlong1983@163.com \\ ${ }^{*}$ Corresponding author
}

Keywords: Polymeric Nano-composite, The Simulation Technology, Theoretical Calculation.

\begin{abstract}
The theoretical studies on the relationship between the structure and properties of polymeric nano-composite (PNC) were reviewed in this paper. Some mechanical properties of the PNC by calculation and simulation technology in recent years were also analyzed. The theoretical study results showed the efficiency and accuracy of the simulation technology about the relationship between the structure and the performance of the PNC. It has been proved that the calculation simulation technology play an important role in prediction and verification for the synthesis and application of the PNC. As the simulation technology can predict the structure and properties, the PNC with excellent performances may be designed and prepared in a short time and high efficiency.
\end{abstract}

\section{Introduction}

Polymeric nano-composite (PNC) is a kind of multiphase materials with interfaces [1]. The PNC are usually made of a polymer and inorganic nano-fillers materials (metal, ceramic, fiber, etc). The biggest advantage of the PNC is that they can obtain the advantage of various materials, such as high strength, light weight, high temperature resistance, corrosion resistance, insulation, and other properties. We can also choose the suitable polymer materials and other materials with some special properties to make the composite materials to meet actual demands[2]. Therefore, it is significant to investigate the relationship between structure and properties of the PNC.

\section{General Instructions}

The PNC are composed of polymer, nano-fillers materials and the interface between them. Polymer is the carrier of nano-fillers, and the mechanical, electrical and thermodynamic properties of PNC can be improved observably by the introduction of nano-fillers. The nano-fillers also has some functions properties, such as electricity [3], magnetism [4], piezoelectric [5], ferroelectric[6], low dielectric[7], and the PNC could possess both the advantages of the matrix and the fillers. The interfaces are the small areas between the polymer and the nano-fillers, which have important effect on the performance of the PNC [8]. Therefore, in order to ensure the perfect performance of the PNC, the interfaces in the PNC should be stable and firm.

Due to the functional diversification of the PNC, the research on the interface has been gradually developed to a multidisciplinary crossing field. Researchers with different academic background have different research orientation on interface structures. Engineers pay attention to the research of practical application, and they are good at finding or producing materials with excellent performances [9]. And the researchers with mathematical background are keen to establish a series of finite element mathematical model to analysis practical problems in the view of qualitative and quantitative $[10,11]$. Chemical researchers investigate the interfacial structures from a microscopic perspective and they usually try to modify the interfacial structures with different chemical bonds [12, 13]. Physics researchers devote themselves to finding effective characterization methods and instruments according to the basic theory [14]. 
In recent years, the research on the interfacial structure of the PNC is more and more deeply. However, in the preparation and testing process, it is difficult for us to compare the reported data because of the various constraints (temperature, pressure, state of aggregation and other factors). At the same time, it is difficult to prepare the ideal interfacial structures in the experiments due to the complexity of the interfacial structures. With the development of computer technology, simulation technology has been developed rapidly. In the research of materials, molecular simulation technology has been an effective method. By using theoretical calculation, the influence of each parameter for material characteristics can be predicted. Molecular simulation technology can simulate the environment which is difficult to be realized or cannot be realized in the lab $[15,16,17]$. Therefore theoretical calculation is an important method to investigate the performance of the PNC with different conditions.

\section{Relationship between Interface Structure and Performance}

The interfaces in the composites, which exist in between the polymer and the nano-fillers (as shown in Fig 1), are an important region for the stress transfer and functional loading of the PNC[18]. From the view of the evaluation on the performance of materials, it is well known that the enhancement efficiency of the nano-fillers increases with the increase of the interfacial stability. But two main factors limit the enhancement efficiency of nano-fillers [19, 20]. On one hand, the specific surface area of the nano-fillers increases with the decrease of the size so that the aggregation possibility of nano-fillers augments. In the polymer, the dispersion of the nano-fillers is poor and the aggregation destroys the overall uniformity of the PNC. When the PNC are affected by the external force (such as heat, electricity), the aggregation regions will be not consistent with the overall response of the PNC, which could destroy the superior performance of the materials and may be the first place to be destroyed. One the other hand, the interfacial interactions between the nano-fillers and the polymer are related to the stability of the composite material. The weaker the interface interaction is, the higher possibility the materials fail. Therefore, in order to improve the dispersion of nano-fillers in the polymer, the stability of the composite material are the problems that cannot be ignored.

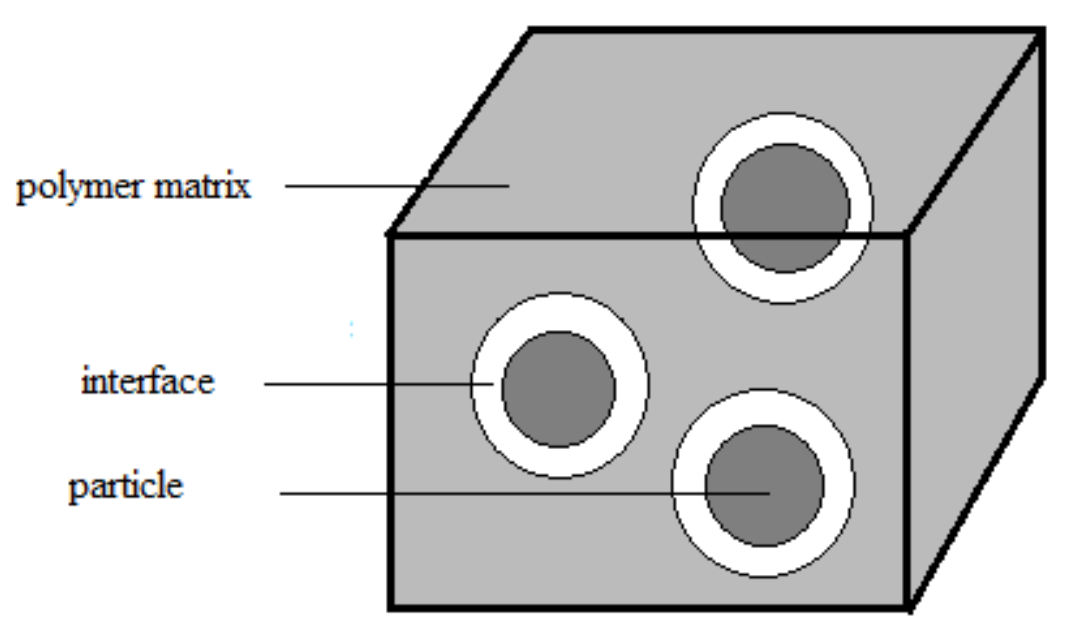

Fig. 1 Schematic illustration of interfacial micro-model

The thermodynamic properties and mechanical properties of Polyimide (PI)/ Cu nano-composites was reported by Wang Xuan et al. [21] with molecular dynamics simulation method. They found that the $\mathrm{PI} / \mathrm{Cu}$ composites were isotropic amorphous structure, and Van der Waals force was the main reason why the nano- $\mathrm{Cu}$ and PI were combined together with makes the composite more stable. The structure, elastic modulus and the interfacial interaction of PI/KTN composites was studied by Lin et 
al. [22] by molecular dynamics simulation. The results showed that the KTN particles and the PI were united with Van der Waals force and the hydrogen bonds. The smaller the KTN size was, the larger the number of atoms on the surface of the KTN was. What's more the smaller KTN size can make the $\mathrm{PI} / \mathrm{KTN}$ interfacial interaction stronger and the PI/KTN Young modulus higher. They also found that doping smaller size nano-KTN was an effective way to improve the mechanical properties of PI.

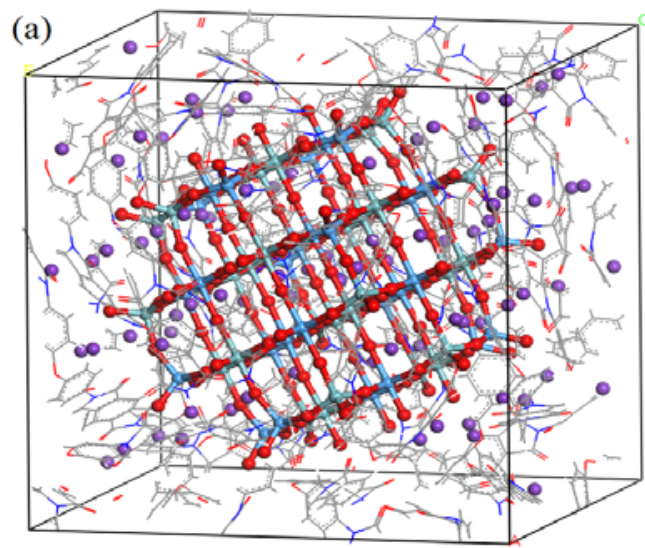

(b)

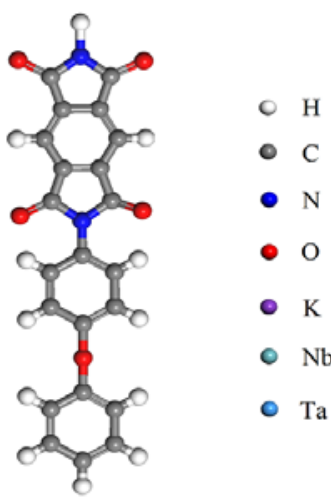

Fig. 2. Model of PI/KTN composite: (a) the whole picture of PI/KTN composite; (b) the molecular structure of PI and the atoms of composites.

\section{Interface Structure Type}

According to the interfaces of nano-fillers in the polymer, there are three types, the mechanical interlocking structure, the immersion structure and the chemical bonding structure.

\section{Mechanical Interlocking Structure}

Mechanical interlocking structure is one of the most basic and traditional theory methods. The method emphasizes that the surface of the two phases can be anchored to form a mechanical interlock structure under the appropriate conditions [23]. For example, nano-SiO2 can be directly dispersed in the polymer by blending at some temperature [24]. As inorganic nano-fillers are unstable systems, the effects of fluid mechanics and surface physical chemistry can make the aggregations dispersed and stabilized again in the blending process. However, phase separation phenomenon will happen if the concentration of nano-fillers is too high.

The adhesion behavior of the interface between polyethylene (PE) and glass fiber (GF) studied by Gao et al. [25] with molecular simulation method. They found that the total energy of PE/GF decreased and the PE/GF system was more stable when the GF were added into PE. The main reason of adhesion behavior was the van der Waals and electrostatic force, as shown in Table 1. When a large number of GF were added into PE, there was a remarkable influence on the adhesion behavior between PE and GF due to exclusion of non-bonded atoms increased in the PE/GF system.

Table 1 PE molecular structure and system energy of the finished interfacial adsorption and joint behaviors of GF/PE under dynamic state

\begin{tabular}{|c|c|c|c|c|c|c|}
\hline \multirow[b]{2}{*}{ Substance } & \multirow{2}{*}{$\begin{array}{l}\text { Average } \\
\text { bond } \\
\text { distance } \\
\text { of } \mathrm{PE} / \AA\end{array}$} & \multirow[b]{2}{*}{$\begin{array}{l}\text { Potential } \\
\text { energy } \\
\left(\mathrm{kcal}^{*} \mathrm{~mol}^{-1}\right)\end{array}$} & \multirow[b]{2}{*}{$\begin{array}{l}\text { Total energy } \\
\left(\mathrm{kcal}^{*} \mathrm{~mol}^{-1}\right)\end{array}$} & \multicolumn{3}{|c|}{ Contributions to Total energy $\left(\mathrm{kcal}^{*} \mathrm{~mol}^{-1}\right)$} \\
\hline & & & & $\begin{array}{l}\text { Valence } \\
\text { energy } \\
\left(\mathrm{kcal}^{*} \mathrm{~mol}^{-1}\right)\end{array}$ & $\begin{array}{l}\text { Van der Waal } \\
\left(\mathrm{kcal}^{*} \mathrm{~mol}^{-1}\right)\end{array}$ & $\begin{array}{l}\text { Electrostatic } \\
\left(\mathrm{kcal}^{*} \mathrm{~mol}^{-1}\right)\end{array}$ \\
\hline $\mathrm{PE}$ & 1.528 & -37.774 & 475.467 & 75.364 & -113.014 & -0.124 \\
\hline GF/PE & 1.553 & -208.764 & 357.000 & 191.872 & -139.370 & -261.266 \\
\hline
\end{tabular}




\section{Immersion Structure}

The immersion theory was presented by Zisman in 1963 [26]. The immersion theory emphasizes that nano-fillers and polymer can achieve compatibility if the surface between nano-fillers and polymer has the similar surface polarity and free energy. In general, the surface modification for nano-fillers (grafting or other chemical modification) is an effective way to realize the compatibility of nano-fillers and polymer.

The model of carbon nanotube (CNT)was studied by Zheng et al. [27]which were modified carboxyl, amide, phenyl and other groups by molecular dynamics simulation, as shown in Fig. 3 and Fig.4. When a small amount of functional groups was modified on the CNT, the shear strength of the pullout process was analyzed. The results showed that the shear strength of the modified CNTs were higher than that of the unmodified CNT. Among the modified functional groups, the CNT with phenyl owned the biggest pullout force, whose shear stress was about 17 times than that of unmodified CNT.
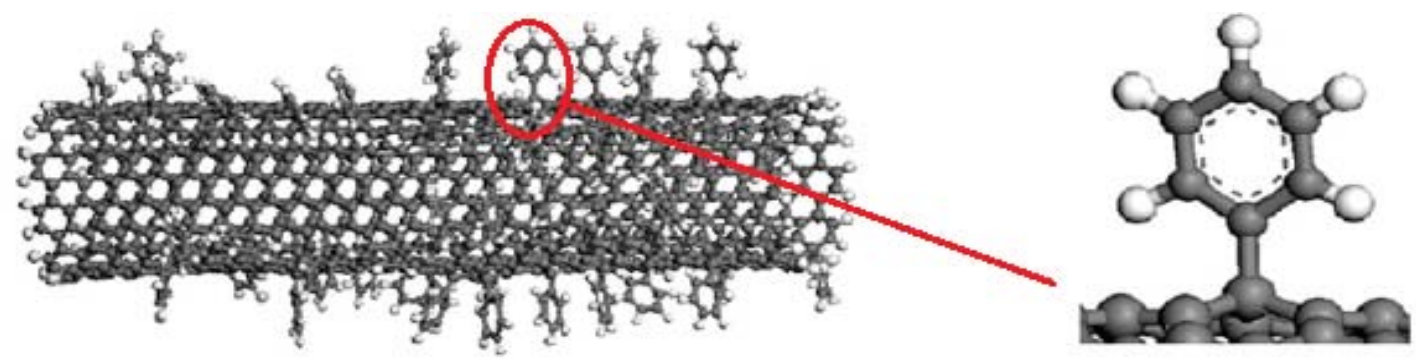

Fig. 3 Illustrating of a CNT with phenyl group randomly

\begin{tabular}{|c|c|c|c|}
\hline shower & 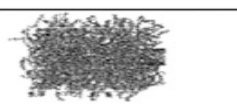 & Whashay & 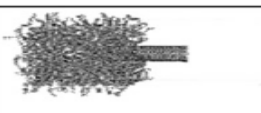 \\
\hline Pull o $\AA$ & Pull 10 A & Pu11 $20 \AA$ & Pull $30 \AA$ \\
\hline Shestif & 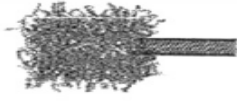 & - & 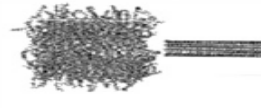 \\
\hline Pull $40 \AA$ & Pull $50 \AA$ & Pull $60 \AA$ & Pull 70 A \\
\hline
\end{tabular}

Fig. 4 Snapshots from the MD simulation of the pullout of the CNT .

\section{Chemical Bonding Structure}

Chemical bond structure is an efficient and stable combination of interfaces, and some chemical bond structure types are shown in Table 2. To form chemical bonds, the key point of chemical bond structure is that the two phase components of the interface should contain functional groups which can react with each other. Chemical bond structure can also be formed on the interface because some coupling agents are introduced in the composites.

Yang et al. [28] set a series models of different sizes $\mathrm{SiO} 2$ in PI to enhance the interfacial loading efficiency and discussed properties of the $\mathrm{PI} / \mathrm{SiO} 2$ models where the oxygen atoms on the surface of the nano-SiO2 and PI were bonded, as shown in Fig.5. They also analyzed the Young modulus, shear modulus, interaction energy and self-diffusion coefficient of the $\mathrm{PI} / \mathrm{SiO} 2$ models. They found that Young modulus and shear modulus were significantly increased than that of non-bonded $\mathrm{PI} / \mathrm{SiO} 2$ models. The smaller $\mathrm{SiO} 2$ size was, the more significant mechanical properties of $\mathrm{PI} / \mathrm{SiO} 2$ were. 
Table 2 Chemical bonding types of PNC.

\begin{tabular}{|l|l|l|}
\hline Types & Combination ways & Cases \\
\hline Covalent bond & $\begin{array}{l}\text { The functional groups of polymer and } \\
\text { functional groups of nano-fillers. }\end{array}$ & $\begin{array}{l}\text { The amino, carboxyl groups on the polyimide } \\
\text { and the hydroxyl groups of the nano- } \mathrm{SiO}_{2} .\end{array}$ \\
\hline Ionic bond & $\begin{array}{l}\text { Polymer chains and nanoparticles with } \\
\text { opposite charges. }\end{array}$ & $\begin{array}{l}\text { Polyaniline and montmorillonite under acidic } \\
\text { conditions. }\end{array}$ \\
\hline $\begin{array}{l}\text { Coordination } \\
\text { bond }\end{array}$ & $\begin{array}{l}\text { Polymer and nano-fillers with electron } \\
\text { pair and space electron orbit can be } \\
\text { matched with each other. }\end{array}$ & $\begin{array}{l}\text { Polyethylene Oxide and } \mathrm{Na}^{+} \text {in the } \\
\text { montmorillonite can form the } \\
\mathrm{PEO}^{+} \mathrm{Na}^{+} \text {clathrate. }\end{array}$ \\
\hline
\end{tabular}

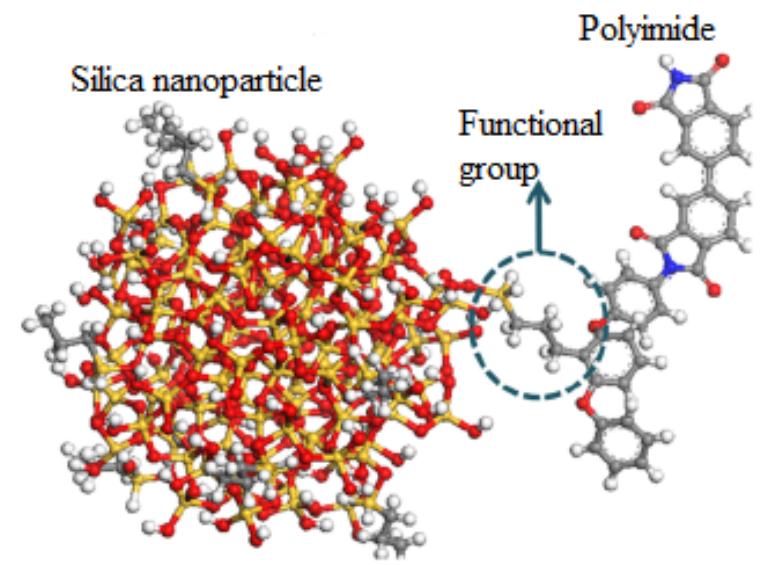

Fig. 5 Covalently grafted $\mathrm{PI} / \mathrm{SiO}_{2}$ nano-composites model

The load transfer mechanism of PE/CNT under compressive loading by molecular dynamics was investigated by Namilae et al. [29], as shown in Fig. 6. The results showed that when the interface of the PE and CNT did not form any chemical bonds, the critical crushing load of PE/CNT was bigger than that of the PE. The critical crushing load of PE/CNT was significantly improved when the interface of the PE and CNT did not form some chemical bonds.

(a)

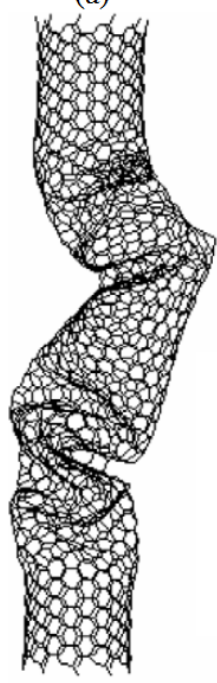

(b)

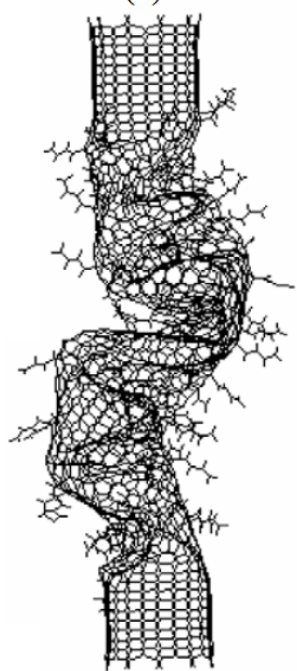

Fig. 6 Simulation snapshots of CNT subject to compression (a) is the free CNT, (b) PE/CNT with chemically bond interface 


\section{Expectation}

In recent years, there have been many research achievements on the interface of the PNC by the simulation method. The simulation technology can help us deeply understand the performance of the PNC. With the improvement of the new material and functional requirements, the simulation technology has gradually become an important way to investigate the relationship between interface structure and properties of the PNC, which have the profound significance for preparing composite materials.

\section{Acknowledgements}

This work was supported by the National Natural Science Foundation of China (Grant NO. 61372013), and Scientific Research Fund of Heilongjiang Provincial Education Department (No. E201258).

\section{References}

[1] Borstnar G, Mavrogordato M N, Yang Q D, et al. Crack path simulation in a particle-toughened interlayer within a polymer composite laminate. Composites Science and Technology, 133(2016)89-96.

[2] Liew K M, Lei Z X, Zhang L W. Mechanical analysis of functionally graded carbon nanotube reinforced composites: a review. Composite Structures, 120(2015)90-97.

[3] Nilsson F, Krückel J, Schubert D W, et al. Simulating the effective electric conductivity of polymer composites with high aspect ratio fillers. Composites Science \& Technology, 132(2016)16-23.

[4] Song W L, Cao M S, Lu M M, et al. Flexible graphene/polymer composite films in sandwich structures for effective electromagnetic interference shielding. Carbon, 66,1(2014)67- 76.

[5] Alexandre M, Bessaguet C, David C, et al. Piezoelectric properties of polymer/lead-free ceramic composites. Phase Transitions, (2016)1-9.

[6] Yang K, Huang X, Huang Y, et al. Fluoro-Polymer@BaTiO3 Hybrid Nanoparticles Prepared via RAFT Polymerization: Toward Ferroelectric Polymer Nanocomposites with High Dielectric Constant and Low Dielectric Loss for Energy Storage Application. Chemistry of Materials, ,25,11(2013)2327-2338.

[7] Zhou Y, Hong W, Lu W, et al. Fabrication and characterization of aluminum nitride polymer matrix composites with high thermal conductivity and low dielectric constant for electronic packaging. Materials Science \& Engineering B, 177,11(2012)892-896.

[8] Shokrieh M M, Rafiee R. On the tensile behavior of an embedded carbon nanotube in polymer matrix with non-bonded interphase region. Composite Structures, 92,3(2010)647-652.

[9] Lin J, Liu Y, Yang W, et al. Structure and mechanical properties of the hybrid films of well dispersed $\mathrm{SiO} 2$ nanoparticle in polyimide $(\mathrm{PI} / \mathrm{SiO} 2)$ prepared by sol - gel process. Journal of Polymer Research, 21,8(2014)1-8.

[10] Frankland S J V, Harik V M, Odegard G M, et al. The stress - strain behavior of polymer nanotube composites from molecular dynamics simulation. Composites Science \& Technology, 63,11(2003)1655-1661.

[11] Vogler M, Rolfes R, Camanho P P. Modeling the inelastic deformation and fracture of polymer composites -Part I: Plasticity model. Mechanics of Materials, 59,3(2013)50-64. 
[12] Ndoro T V M, Voyiatzis E, Ghanbari A, et al. Interface of Grafted and Ungrafted Silica Nanoparticles with a Polystyrene Matrix: Atomistic Molecular Dynamics Simulations. Macromolecules, 44,7(2011)2316-2327.

[13] Eslami H, Rahimi M, Müller-Plathe F. Molecular dynamics simulation of a silica nanoparticle in oligomeric poly (methyl methacrylate): a model system for studying the interphase thickness in a polymer - nanocomposite via different properties. Macromolecules, 46,21(2013)8680-8692.

[14] Vu-Bac N, Lahmer T, Zhang Y, et al. Stochastic predictions of interfacial characteristic of polymeric nanocomposites (PNCs). Composites Part B Engineering, 59,3(2014)80-95.

[15] Shindo Y, Yu K, Takeda T, et al. Electrical resistance change and crack behavior in carbon nanotube/polymer composites under tensile loading. Compos Part B Eng. Composites, $22,43(2012) 3845-3852$.

[16] Totry E, Molina-Aldareguía J M, González C, et al. Effect of fiber, matrix and interface properties on the in-plane shear deformation of carbon-fiber reinforced composites. Composites Science \& Technology,70,6(2010)970-980.

[17] Li C, Strachan A. Molecular simulations of crosslinking process of thermosetting polymers. Polymer, 51,25(2010)6058-6070.

[18] Gibson R F. A review of recent research on mechanics of multifunctional composite materials and structures. Composite Structures, 92,12(2010)2793-2810.

[19] Liu J, Gao Y, Cao D, et al. Nanoparticle dispersion and aggregation in polymer nanocomposites: insights from molecular dynamics simulation.Langmuir the Acs Journal of Surfaces \& Colloids, 27,12(2011)7926-33.

[20] Peng R D, Zhou H W, Wang H W, et al. Modeling of nano-reinforced polymer composites: Microstructure effect on Young' s modulus. Computational Materials Science, 60(2012)19-31.

[21] Wei-feng Sun, Xuan Wang et al. Polyimide/cu nanoparticles composites of molecular dynamics simulation study.Journal of Physics, 18(2013)358-366.

[22]Jia-qi Lin , Xiao-kang Li , Wen-longYang ,et al. Polyimide/tantalum niobium acid potassium nanoparticles composites structure and mechanical properties of molecular dynamics simulation. Acta Physica Sinica,64,12 (2015)126202-8.

[23] Tallury S S, Pasquinelli M A. Molecular Dynamics Simulations of Flexible Polymer Chains Wrapping Single-Walled Carbon Nanotubes. Journal of Physical Chemistry B, 114,12(2010), 4122-9.

[24] Odegard G M, Clancy T C, Gates T S. Modeling of the mechanical properties of nanoparticle/polymer composites. Polymer,46,2(2005)553-562.

[25] Jun Gao, Wei Hong. Molecular simulation studies of fiberglass reinforced polyethylene interface behavior. Computer and applied chemistry, 24,04(2007)493-497.

[26] Zisman, Wm A.Relation of the equilibrium contact angle to liquid and solid constitution. Adv. Chem. Ser,43,1(1964).

[27] Zheng Q, Dan X, Xue Q, et al. Computational analysis of effect of modification on the interfacial characteristics of a carbon nanotube-polyethylene composite system. Applied Surface Science , 255,6,(2009)3534-3543. 
[28] Yang S, Choi J, Cho M. Elastic stiffness and filler size effect of covalently grafted nanosilica polyimide composites: molecular dynamics study. Acs Applied Materials \& Interfaces, 4,9(2012), 4792-9.

[29] Namilae S, Chandra N. Role of Atomic Scale Interfaces in the Compressive Behavior of Carbon Nanotubes in Composites. Composites Science \& Technology, 66,13(2006) 2030-2038. 